\title{
C. Vandermotten (dir.), 2003, La production des espaces économiques, tome 2
}

Éditions de l'Université de Bruxelles, 296 p.

\section{Stéphane Rosière}

\section{OpenEdition \\ Journals}

Édition électronique

URL : http://journals.openedition.org/rge/2519

DOI : $10.4000 /$ rge.2519

ISSN : 2108-6478

Éditeur

Association des géographes de l'Est

Édition imprimée

Date de publication : 1 janvier 2003

ISSN : 0035-3213

Référence électronique

Stéphane Rosière, «C. Vandermotten (dir.), 2003, La production des espaces économiques, tome 2 », Revue Géographique de l'Est [En ligne], vol. 43 / 1-2 | 2003, mis en ligne le 08 décembre 2010, consulté le 25 septembre 2020. URL : http://journals.openedition.org/rge/2519; DOI : https://doi.org/10.4000/ rge. 2519

Ce document a été généré automatiquement le 25 septembre 2020.

Tous droits réservés 


\section{Vandermotten (dir.), 2003, La production des espaces économiques, tome 2}

Éditions de l'Université de Bruxelles, 296 p.

Stéphane Rosière

\section{RÉFÉRENCE}

C. Vandermotten (dir.), 2003, La production des espaces économiques, tome 2, Éditions de l'Université de Bruxelles, $296 \mathrm{p}$.

1 Le tome 2 de "La production des Espaces économiques", sous la direction de Christian Vandermotten et Pierre Marissal, parachève l'étude des aires géographiques et des problématiques économiques contemporaines. Si le tome 1, publié en 1998, envisageait essentiellement l'Europe et des thèmes généraux comme une très inté ressante analyse de la répartition de la richesse à l'échelle mondiale, le tome 2 est, lui, centré sur les États-Unis et la « périphérie » mondiale (les pays sous-développés).

Dans ce nouveau volume les auteurs abordent successivement les conditions socioéconomiques dans la périphérie, le lien entre croissance démographique et développement, la formation du système de l'économie-monde, et les structures spatiales dans les pays de la périphérie, reflets de leurs modalités d'insertion dans l'économie monde. Ce deuxième tome souligne à quel point «les conditions d'insertion dans l'économie-monde (...) ont en général tendance à augmenter les concentrations spatiales au profit des capitales ou des régions métropolitaines» ( $\mathrm{p}$. 274). Cette concentration, dont les modalités varient suivant les pays, pose donc la question de la centralité excessive abordée aussi par Baudelle et Castagnède dans « le polycentrisme en Europe ». Le renforcement des gradients de richesse est très bien souligné par les analyses de Vandermotten et Marissal. Leur conclusion est d'ailleurs pessimiste : cette réalité contemporaine " est bien éloignée des mythiques théories 
de l'équilibre spatial. Contrairement aux thèses mécanistes avancées par un économiste comme Rostow, il apparait que les possibilités de rattrapage sont illusoires pour la plupart des pays pauvres, même sur le moyen terme, dans les conditions actuelles de fonctionnement de l'ordre économique " (p. 281). Mise en place d'un développement durable, transformation des modes de consommation, etc. : les modalités d'un "autre développement » restent à mettre en place.

Outre la rigueur des analyses, chaque thème est illustré par de très nombreuses cartes d'excellente facture (plus de cent dans le second volume), ainsi que des tableaux et des illustrations en tout genre (mais pas de photos). La plupart des thèmes contemporains de la géographie économique sont ici abordés avec clarté. Cet ouvrage, doté d'une présentation soignée paraît indispensable à toutes les bibliothèques de géographie, d'économie voire d'histoire (les processus présentés le sont toujours d'une façon chronologique), ainsi qu'aux étudiants se destinant à ces problématiques alors que l'aspect géographique et spatial est souvent délaissé lorsque l'on aborde la mondialisation. Pourtant, et c'est l'un des mérites de ce livre, l'espace apparait comme un révélateur pertinent des inégalités engendrés par les processus économiques contemporains.

\section{AUTEUR \\ STÉPHANE ROSIÈRE}

Université Nancy 2 